\title{
Presentación
}

\section{Qhapaq Nan I, Taller Internacional en torno al Sistema Vial Inkaico}

Desde el año 2000 en adelante se visualizan en la América andina los lugares donde el Tawantinsuyu dejó sus diversos testimonios y un creciente interés por desentrañar el repertorio vial del Inka, constituyéndose en una línea de investigación que ha aportado al conocimiento de una de las expresiones culturales que caracterizó al Estado Inka. Esta preocupación analítica arranca desde la obra fundacional de Regal en Perú, que prosiguen Levillier, Strube Erdmann, Raffino, Hyslop y una serie de connotados investigadores hasta el presente. A este fecundo trabajo se sumó en 2001 el Proyecto Qhapaq Ñan, que impulsara Perú y que sumó a Colombia, Ecuador, Bolivia, Argentina y Chile, logrando conjuntamente en 2014 la nominación del Camino Principal Andino como Patrimonio Mundial por parte de la UNESCO.

No obstante, y junto con los alcances críticos que han emanado desde la academia, apreciamos también una omisión de la esfera investigativa del camino en este proyecto, en prácticamente todos los países referidos. ${ }^{1}$ Por otro lado, se observa que los conceptos y los criterios para registrar, estudiar e interpretar esta clase de evidencias varían de acuerdo al enfoque analítico de cada investigador o de los objetivos de un proyecto en particular, no siendo muchas veces el centro de la focalización analítica. De igual forma, no existía el conocimiento entre los investigadores sudamericanos sobre cuáles eran las características viales específicas, variabilidades y probables significaciones del conjunto vial andino. Esto redundaba en la falta de una instancia académica, independiente, que congregara a los especialistas que investigan el Qhapaq Ñan para presentar sus trabajos y exponer sus problemas.

A raíz de lo señalado, en un colectivo de colegas del subcontinente surgió la necesidad de implementar un encuentro internacional, tipo taller, que acogiera estas inquietudes. Así, en 2014 se formó un Comité Organizador compuesto por diez miembros de Ecuador, Perú, Bolivia, Argentina y Chile, quienes precisaron los criterios para definir a los invitados (trayectoria y especialización en el tema), la orgánica del taller y sus objetivos. Como Chile fue el gestor inicial del evento, este finalmente se realizó los días 23 al 26 de marzo de 2015 en San Pedro de Atacama, denominándose "Qhapaq Ñan I, Taller Internacional en torno al Sistema Vial Inkaico". Contó con 25 expositores de los seis países que formaron parte del otrora Tawantinsuyu, como también con 45 asistentes provenientes de Perú, Argentina y Chile.

1 Excepción al respecto lo constituye el Ministerio de Cultura de Perú, que desarrolla trabajos permanentes de investigación, conservación y educación en torno al Qhapaq Ñan peruano, con la participación de las comunidades locales. 
El taller tuvo el patrocinio del Museo Chileno de Arte Precolombino, la Universidad Arturo Prat, la Universidad Católica del Norte, la Universidad Nacional de Salta, el Instituto Francés de Estudios Andinos, el Programa de Postgrado en Antropología de la Universidad Católica del Norte y Universidad de Tarapacá, y del Centro de Investigaciones del Hombre en el Desierto de la Universidad de Tarapacá. Los departamentos de antropología de la Universidad de Chile y de la Universidad de Tarapacá, la Sociedad Chilena de Arqueología y la revista Inka Llaqta apoyaron igualmente el taller. Además, colaboraron las secretarias técnicas del Proyecto Qhapaq Nan del Ministerio de Cultura de Perú y de la Universidad de Nariño de Colombia.

La reunión puso de manifiesto la importancia de la comunicación directa entre los estudiosos del camino, junto con la necesidad de conocer sus avances investigativos, discutiéndose aspectos teóricos, metodológicos e interpretativos. La ordenación de las mesas por países permitió que todos los participantes tuvieran un panorama global tanto del Qhapaq Ñan como de sus características esenciales. También se generó el último día una instancia donde se compartieron ideas y experiencias de campo, concurriendo ponentes y asistentes a distintos puntos del camino inka en el Alto Loa.

En consecuencia, consideramos relevante la realización del taller, ya que concentró el quehacer investigativo arqueológico en torno el tema, destacándose como un definido objeto de estudio dentro de la llamada arqueología vial, pero que no se encuentra ajeno a la ocupación inkaica de un territorio. En este proceso se destacó que las poblaciones locales no son pasivas y que los inkas ocuparon rutas preexistentes, en conjunto con la implementación de nuevos caminos. En segundo término, se obtuvo un actualizado estado del arte sobre el particular, dando cuenta de problemáticas globales e individuales. En tercer lugar, se trazaron algunas temáticas a tratar en futuras versiones del taller. Por último, se logró "unidad en la diversidad", siendo posible delinear las singularidades de una comunidad científica que comenzó a fortalecerse en las jornadas de trabajo y en las variadas actividades de camaradería. Asimismo, se acordó que los trabajos expuestos fueran sometidos a un proceso de revisión por pares calificados. Este propósito se cumple con la presente edición a modo de actas del taller, las cuales comprenden los dos volúmenes de 2017 del Boletín del Museo Chileno de Arte Precolombino.

El encuentro fue dedicado a la memoria y obra del colega argentino Ángel Amilcar Alberto Manzo, uno de los impulsores del taller y miembro del Comité Organizador, fallecido repentinamente a fines de septiembre de 2014. En el ámbito de los reconocimientos, por unanimidad el Comité Organizador realizó un homenaje al colega argentino Dr. J. Roberto Bárcena el día 24 de marzo, por sus importantes trabajos dedicados por más de 40 años al conocimiento del camino inka en Argentina, cuyos detalles se presentan a continuación. 